\title{
Dietary curcumin supplementation attenuates 1-methyl-4-phenyl- 1,2,3,6-tetrahydropyridine (MPTP) neurotoxicity in C57BL mice
}

\author{
Xi-Jun $\mathrm{He}^{1,2^{*}}$, Kazuyuki Uchida ${ }^{2}$, Chiaki Megumi ${ }^{3}$, Nobuaki Tsuge ${ }^{3}$, and Hiroyuki Nakayama ${ }^{2 *}$ \\ ${ }^{1}$ State Key Laboratory of Veterinary Biotechnology, Harbin Veterinary Research Institute, Chinese Academy of Agricultural \\ Sciences, Harbin, 150001 People's Republic of China \\ ${ }^{2}$ Department of Veterinary Pathology, Graduate School of Agricultural and Life Sciences, University of Tokyo, 1-1-1 Yayoi, \\ Bunkyo-ku, Tokyo 113-8657, Japan \\ ${ }^{3}$ Somatech Center, House Foods Corporation, 1-4 Takanodai, Yotsukaido, Chiba 284-0033, Japan
}

\begin{abstract}
Studies in vivo and in vitro suggest that curcumin is a neuroprotective agent. Experiments were conducted to determine whether dietary supplementation with curcumin has neuroprotective effects in a mouse model of Parkinson's disease (PD). Treatment with 1-methyl-4-phenyl-1,2,3,6-tetrahydropyridine (MPTP) significantly induced the loss of dopaminergic cells in the substantia nigra and deletion of dopamine in the striatum, which was attenuated by long-term ( 7 weeks) dietary supplementation with curcumin at a concentration of $0.5 \%$ or $2.0 \%(\mathrm{w} / \mathrm{w})$. Although curcumin did not prevent the MPTP-induced apoptosis of neuroblasts in the subventricular zone (SVZ), it promoted the regeneration of neuroblasts in the anterior part of the SVZ (SVZa) at 3 days after MPTP treatment. Furthermore, curcumin enhanced the MPTP-induced activation of microglia and astrocytes in the striatum and increased the expression of glial cell line-derived neurotrophic factor (GDNF) and transforming growth factor- $\beta 1$ (TGF $\beta 1$ ) in the striatum and SVZ. GDNF and TGF $\beta 1$ are thought to play an important role in protecting neurons from injury in the central and peripheral nervous systems. These results suggest that long-term administration of curcumin blocks the neurotoxicity of MPTP in the nigrostriatal dopaminergic system of the mouse and that the neuroprotective effect might be correlated with the increased expression of GDNF and TGF $\beta 1$. Curcumin may be effective in preventing or slowing the progression of PD. (DOI: 10.1293/tox.2015-0020; J Toxicol Pathol 2015; 28: 197-206)
\end{abstract}

Key words: MPTP, curcumin, neuroprotective, dopamine, astrocyte, microglia

\section{Introduction}

Treatment with 1-methyl-4-phenyl-1,2,3,6-tetrahydropyridine (MPTP) is known to selectively deplete striatal dopamine and cause damage to dopaminergic neurons in the substantia nigra pars compacta (SNpc) in humans ${ }^{1}$, nonhuman primates ${ }^{1}$ and several species of rodents ${ }^{2,3}$. To date, MPTP-treated mice remain the best-characterized model of Parkinson's disease (PD) and have provided the strongest support for the role of oxidative stress in the disease's pathogenesis ${ }^{4}$. Moreover, the activation of microglia and astrocytes, another significant and important change in response to MPTP ${ }^{5}$, has also been suggested to be involved in the neurotoxicity of MPTP in the nigrostriatal dopamine system $^{6,7}$. In addition, MPTP has been demonstrated to induce

Received: 21 April 2015, Accepted: 26 June 2015

Published online in J-STAGE: 27 July 2015

*Correspoinding authors: H Nakayama

(e-mail: anakaya@mail.ecc.u-tokyo.ac.jp)

X He (e-mail: hexijun@caas.cn)

(C2015 The Japanese Society of Toxicologic Pathology

This is an open-access article distributed under the terms of the Creative Commons Attribution Non-Commercial No Derivatives (by-ncnd) License $<$ http://creativecommons.org/licenses/by-nc-nd/3.0/> . apoptosis of neuroblasts in the subventricular zone (SVZ) and rostral migratory stream (RMS) in adult mice $\mathrm{e}^{8-10}$.

Curcumin is a constituent of turmeric, the yellow pigment isolated from Curcuma longa and a major ingredient of curry. Curcumin has been scientifically proven to have strong antioxidative, anti-inflammatory and anticarcinogenic properties ${ }^{11}$. In recent years, neuroprotective effects of curcumin have been widely investigated, and numerous studies have shown that curcumin is neuroprotective in multiple animal models and has great potential for prevention or treatment of age-related dementia arising from Alzheimer disease (AD) or cardiovascular disease, $\mathrm{PD}$, other diseases of aging and aspects of aging itself ${ }^{12}$.

In the past few years, however, only a few in vivo and in vitro studies have focused on the effects of curcumin on the toxicity of MPTP or 1-methyl-4-phenylpyridinium $\left(\mathrm{MPP}^{+}\right)$ to try to explore whether curcumin might be a potential preventive and therapeutic agent for PD. Sawada et al. ${ }^{13}$ proved that curcumin, acting as an inhibitor of $c$-Jun/AP-1, protected dopaminergic neurons from $\mathrm{MPP}^{+}$-induced neuronal death. Results from another in vitro study suggest that the cytoprotective effects of curcumin on $\mathrm{MPP}^{+}$-induced cytotoxicity and apoptosis are mediated, at least in part, by the Bcl-2-mitochondria-reactive oxygen species (ROS)-induc- 
ible nitric oxide synthase (iNOS) pathway ${ }^{14}$. Vajragupta et $a l .{ }^{15}$ provided evidence showing that acute treatment with curcumin significantly attenuated MPTP-induced striatal dopamine depletion in adult mice. In another in vivo study, MPTP-induced glutathione (GSH) depletion and lipid peroxidation in the mouse striatum and midbrain was blocked by curcumin treatment ${ }^{16}$. Short-term treatment with curcumin in adult mice can also reverse MPTP-induced depletion of dopamine and 3,4-dihydroxyphenylacetic acid $(\mathrm{DOPAC})^{17}$. As noted in a recent paper, curcumin protected against MPTP- or $\mathrm{MPP}^{+}$-induced dopaminergic neurotoxicity in C57BL/6N mice or SH-SY5Y cells by inhibiting $c$-Jun N-terminal kinase (JNK) pathways both in vivo and in vitro ${ }^{18}$. These investigations mostly focused on the neuroprotective mechanism of curcumin, and they suggest that its protective effects on MPTP/MPP ${ }^{+}$toxicity are mainly related to its antioxidative properties. Moreover, in studies in vivo, curcumin was delivered via intraperitoneal injections and an acute or sub-acute protocol was usually used. As a food additive, the long-term effect of curcumin has not been investigated in the MPTP mouse model of PD. In the present study, curcumin was administered as a dietary supplement, and its neuroprotective effects on MPTP-induced destruction of the nigrostriatal dopamine system were studied in mice. Moreover, the effects of curcumin on the apoptosis of neuroblasts, regeneration of neuroblasts and activation of microglia and astrocytes in MPTP-treated mice were also investigated.

\section{Materials and Methods}

\section{Chemicals and animals}

The curcumin (technical grade) used in this study was a commercially available preparation obtained from Cayman Chemical Company, Ann Arbor, MI, USA. MPTP was purchased from Sigma (St. Louis, MO, USA) and dissolved in saline at a concentration of $4 \mathrm{mg} / \mathrm{ml}$. Three-weekold male C57BL/6 mice (9-12 g; Clea Japan, Tokyo, Japan) were housed five or six per cage in a temperature-controlled room under a 12/12 h light/dark cycle. They were fed a basal diet, Oriental MF (Oriental Yeast Co. Ltd., Tokyo, Japan), supplemented with curcumin.

\section{Experimental design}

All mice had free access to water and food. They were fed the basal diet, a $0.5 \%$ curcumin-supplemented diet, or a $2 \%$ curcumin-supplemented diet. After seven weeks, they were intraperitoneally injected with a single dose of MPTP $40 \mathrm{mg} / \mathrm{kg}$ body weight or saline ( $1 \mathrm{ml} / 100 \mathrm{~g}$ body weight). Thus, they were divided into six groups $(n=10-14$ for each group): group 1, fed the basal diet and injected with saline; group 2 , fed the $0.5 \%$ curcumin diet and injected with saline; group 3 , fed the $2 \%$ curcumin diet and injected with saline; group 4, fed the basal diet and injected with MPTP; group 5 , fed the $0.5 \%$ curcumin diet and injected with MPTP; and group 6 , fed the $2 \%$ curcumin diet and injected with MPTP. Animals were sacrificed at 1 day or 3 days after the MPTP or saline treatment $(n=5-7$ for each group at each time point). All procedures were approved by the Committee of Animal Experiments, Graduate School of Agricultural and Life Science, The University of Tokyo.

\section{Tissue preparation}

The animals were perfused through the heart with sterilized saline followed by $10 \%$ cooled neutral buffered formalin for $5 \mathrm{~min}$ under inhalation anesthesia. The brains were isolated immediately in $10 \%$ neutral buffered formalin, embedded in paraffin and cut into $4-\mu \mathrm{m}$ coronal sections encompassing the entire SVZ for detecting striatal dopamine and neuroblast apoptosis and coronal sections encompassing the entire mesencephalon for detecting dopaminergic neurons in the SNpc. The sections were used for terminal deoxynucleotidyl transferase dUTP nick end labeling (TUNEL), immunohistochemistry and immunofluorescence histochemistry, as well as for staining with hematoxylin-eosin (HE).

\section{Immunohistochemistry}

Tissue sections were used for immunohistochemistry with the following primary antibodies: goat anti-doublecortin (Dcx, 1:200; Santa Cruz Biotechnology, Dallas, TX, USA) as a marker for migrating neuroblasts; rabbit anti-glial fibrillary acidic protein (GFAP, 1:100; Dako, Carpinteria, CA, USA) as a marker for astrocytes; rabbit anti-tyrosine hydroxylase (TH, 1:100; Chemicon, Temecula, CA, USA) and rabbit anti-dopamine transporter (DAT, 1:50, Santa Cruz Biotechnology, Dallas, TX, USA) as dopaminergic markers, rabbit anti-ionized calcium-binding adaptor molecule 1 (Iba 1, 1:250; Wako, Osaka, Japan) as a marker for microglial cells, mouse anti-proliferation cell nuclear antigen (PCNA, 1:100, Dako, Carpinteria, CA, USA), rabbit anti-glial cell line-derived neurotrophic factor (GDNF, 1:50, Santa Cruz Biotechnology, Dallas, TX, USA), and rabbit anti-transforming growth factor beta1 (TGF $\beta 1,1: 50$, Santa Cruz Biotechnology, Dallas, TX, USA). A DAKO EnVision System (Dako EnVision-labeled polymer, peroxidase) was used for detection or binding of the biotinylated secondary antibody. The sections were visualized using $0.05 \% 3,3^{\prime}$-diaminobenzidine (DAB) with $0.03 \%$ hydrogen peroxide in Tris-HCl buffer and counterstained with methyl green.

\section{TUNEL method}

Representative paraffin-embedded sections encompassing the entire SVZ obtained from mice sacrificed at 1 day after MPTP or saline treatment were processed for the TUNEL assay, which was performed using an ApopTag Peroxidase In situ Apoptosis Detection Kit (Chemicon International, Temecula, CA, USA) according to the manufacturer's instructions.

\section{Double-labeling immunofluorescence}

To investigate the effects of curcumin on the regeneration of neuroblasts after MPTP-induced destruction in the SVZ, double-labeling immunofluorescence histochemistry 
was performed using the goat anti-Dcx antibody (Santa Cruz Biotechnology) and mouse anti-PCNA antibody (Dako). Tissue sections were visualized with fluorescein isothiocyanate (FITC)-conjugated donkey anti-goat IgG (1:100; Santa Cruz Biotechnology) and Texas Red-conjugated antigoat antibody (1:100; Vector Laboratories, Burlingame, CA, USA), mounted with Vectashield (Vector Laboratories), and then observed using a Zeiss LSM510 confocal laser scanning microscope.

\section{Cell counting and statistical analysis}

Serial coronal sections through the SVZ ( 0.50 to 0.98 $\mathrm{mm}$ from the bregma) and SNpc ( -2.9 to $-3.3 \mathrm{~mm}$ from the bregma) were collected with the aid of the mouse brain at$\operatorname{las}^{19}$. At least one of ten to fifteen sections (a total of 5-7 sections per animal) was blindly counted for the quantitative analysis. Quantitative densitometric analysis of DAT+ fibers in the striatum was performed using ImageJ (NIH, Bethesda, MD, USA). Results were expressed as the average number (or value) in the unilateral SNpc, SVZ or striatum and reported as the mean \pm standard deviation (SD). Differences between groups were analyzed by ANOVA followed by Tukey's multiple comparison test using the GraphPad Prism statistical software (version 4.00; GraphPad Software Inc, San Diego, CA, USA). The results were considered statistically significant when $p<0.05$.

\section{Results}

\section{Dietary curcumin alone has no detrimental effect on internal organs}

The $2 \%$ but not $0.5 \%$ curcumin-supplemented diet was associated with a small but significant decline in final body weight compared with the control $(23.17 \pm 1.64$ versus 24.75 $\pm 1.44, p<0.002$ ), possibly due to decreased food intake. Although curcumin has been reported to cause hepatotoxicity $^{20}$ or gastric ulceration ${ }^{21}$, mice fed the $0.5 \%$ or $2 \%$ diet for 7 weeks did not show any significant change in the liver, stomach or other organs in our histopathological analysis.

\section{MPTP-induced neurotoxicity in the nigrostriatal do- paminergic system is attenuated by dietary curcumin}

To investigate the neuroprotective effects of curcumin on the MPTP-induced damage in the nigrostriatal dopaminergic system, C57BL/6 mice were fed a diet supplemented with $0.5 \%$ or $2 \%$ curcumin for 7 weeks and then given a single dose of MPTP (40 mg/kg, i.p.). Three days after the MPTP treatment, the brains were analyzed by immunohistochemistry to quantify TH-positive neurons in the SNpc. In mice fed the basal diet, MPTP treatment reduced the number of TH-positive neurons to $41.6 \%$ of that in the saline-treated control $(p<0.001)$ (Fig.1A, B and E). In mice fed the diet supplemented with $0.5 \%$ or $2 \%$ curcumin, however, the neurotoxicity of MPTP was blocked, as revealed by a significantly attenuated decrease in the number of THpositive dopaminergic neurons, ranging from $59.7 \%(0.5 \%$ curcumin) to $68.3 \%$ ( $2 \%$ curcumin) of the control (without curcumin) value $(p<0.05$ and $p<0.002$, respectively, when compared with MPTP-treated mice fed the basal diet) (Fig. $1 \mathrm{~A}-\mathrm{E})$. Since there was no significant difference in the number of TH-positive dopaminergic neurons between the $0.5 \%$ and $2 \%$ curcumin groups after the MPTP treatment (Fig. $1 \mathrm{C}-\mathrm{E}$ ), curcumin's attenuating effect on the neurotoxicity of MPTP was thought not to be dose dependent when administered at $0.5 \%$ to $2 \%$. Mice fed curcumin and injected with saline showed no change in the number of TH-positive dopaminergic neurons.

We further analyzed changes in dopamine levels in the striatum by performing an immunohistochemical analysis with DAT antibody. MPTP-treated mice exhibited patterns of DAT-immunoreactive fiber loss, as shown in Fig. 1G, at 3 days post treatement compared with the control (without curcumin) (Fig. 1F). Supplementation of the diet with $0.5 \%$ or $2 \%$ curcumin for 7 weeks significantly blocked the MPTP-induced depletion of striatal dopamine content (Fig. $1 \mathrm{~F}-\mathrm{J})$.

Dietary curcumin promotes the recruitment of neuroblasts in the anterior part of the SVZ post treatment with MPTP

We previously demonstrated that the injection of MPTP induced apoptosis of neuroblasts in the SVZ and RMS of adult mice ${ }^{8,10}$. The present results show that a diet supplemented with curcumin did not protect neuroblasts against MPTP-induced apoptosis when examined at 24 hours post treatment (Fig. 2).

In mice fed the basal diet, MPTP-induced apoptosis was followed by a dramatic reduction in the number of neuroblasts in the anterior part of the SVZ (SVZa), as shown in Fig. 3B, F, J and $\mathrm{N}$ and Fig. 4. Unexpectedly, at 3 days post treatment with MPTP, the number of neuroblasts was not decreased in mice fed the diets supplemented with curcumin (Fig. 3C and D, G and H, K and L and $\mathrm{O}$ and P, Fig. 4). Since MPTP-induced apoptosis was not blocked in the curcumin-fed groups, this may be attributed to enhanced regeneration of neuroblasts. Representative HE-stained sections obtained from mice fed $0.5 \%$ (Fig. 3C) and 2\% (Fig. 3D) curcumin showed unchanged cell numbers compared with those from saline-treated mice fed the basal diet (Fig. 3A). Immunohistochemical analysis with Dcx antibody (Fig. 3E-H) revealed that MPTP induced a decrease in the number of Dcx-positive neuroblasts in the SVZa (40.7 $\pm 6.5 \%$ of control) (Fig. 3F, Fig. 4), which was blocked in the $0.5 \%$ curcumin $(107.6 \pm 13.1 \%$ of control) (Fig. 3G, Fig 4 ) and $2 \%$ curcumin $(113.3 \pm 17.2 \%)$ groups (Fig. $3 \mathrm{H}$ and Fig. 4). To further assess cellular regeneration, we immunohistochemically labeled cells in the SVZa using PCNA antibody (Fig. 3I-L). At 3 days post treatment with MPTP, the numbers of PCNA-positive cells were greatly increased in the curcumin-fed groups $(92.7 \pm 9.5 \%$ and $101.5 \pm 10.9 \%$ of control, respectively) (Fig. 3K and L, Fig. 4) compared with the basal diet-fed group $(33.1 \pm 7.9 \%$ of control) (Fig. 3J, Fig. 4). To visualize the phenotype of the cells underlying the proliferation, we performed double labeling with 

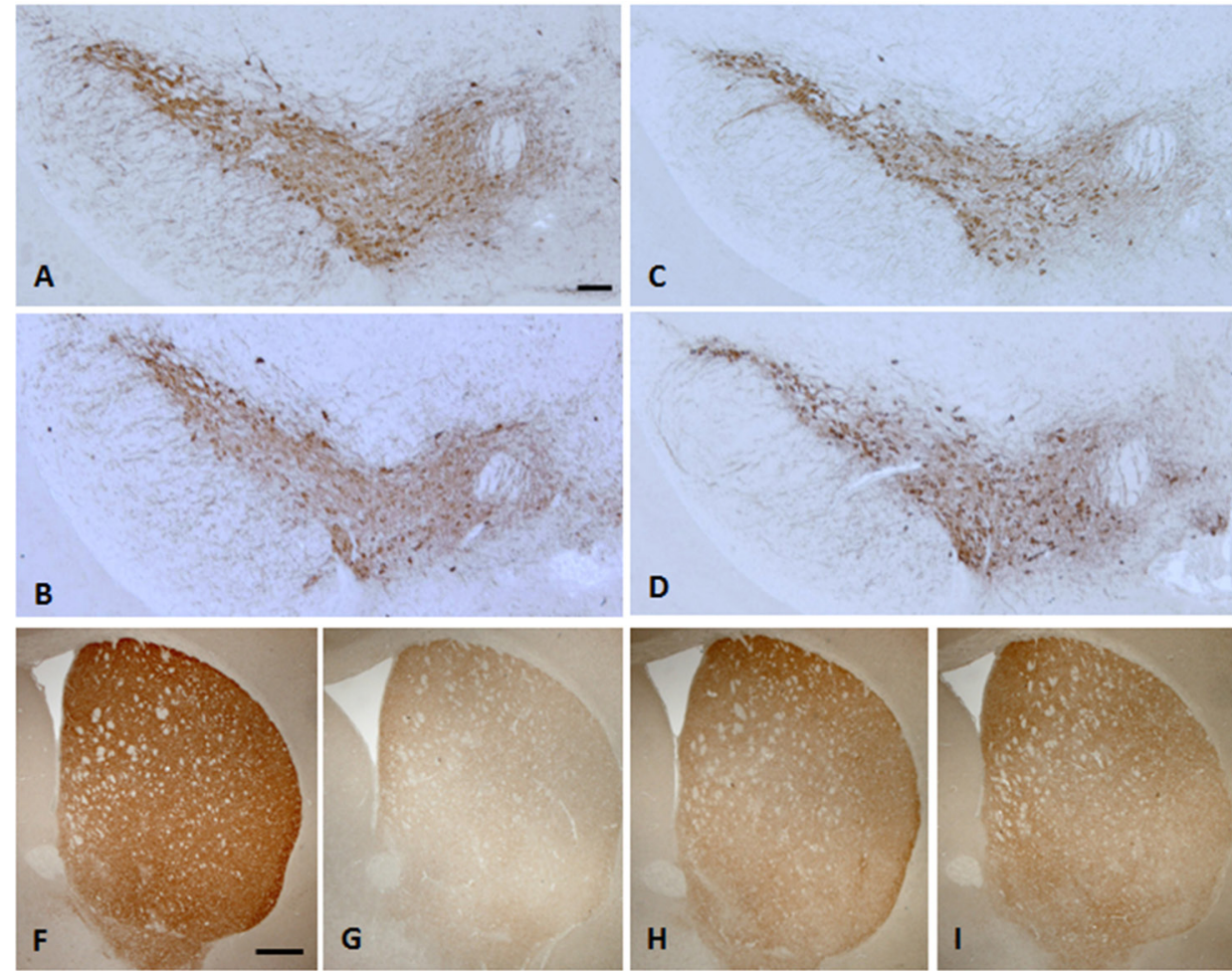

$\mathbf{E}$

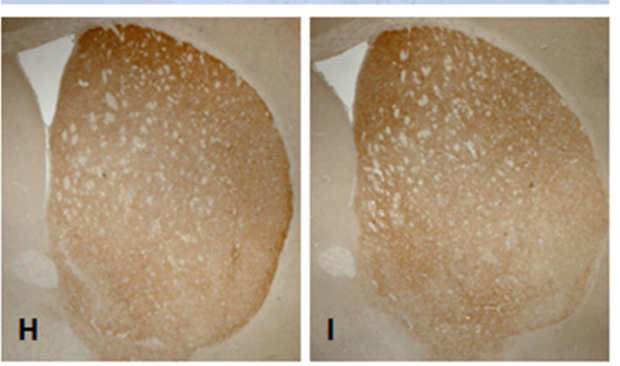

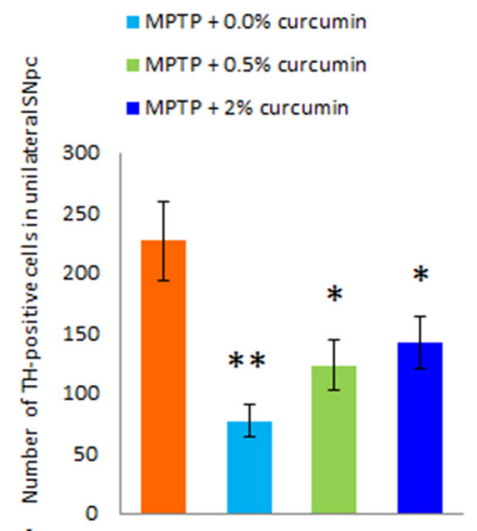

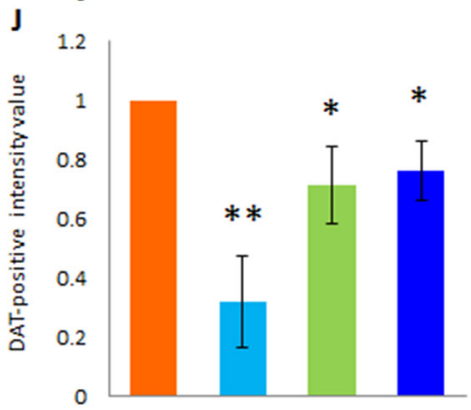

Fig. 1. Effect of dietary curcumin supplementation on MPTP-induced destruction of the nigrostriatal dapaminergic system of mice shown by results of TH or DAT immunostaining. (A and F) Control group (basal diet + saline treatment). (B and G) Animals fed the basal diet and treated with MPTP showed a severe loss of dopaminergic neurons in the SNpc (B) and dopamine depletion in the striatum (G). (C and H) Animals fed a diet supplemented with $0.5 \%(w / w)$ curcumin for 7 weeks and then treated with MPTP. (D and I) Animals fed a diet supplemented with $2 \%(\mathrm{w} / \mathrm{w})$ curcumin for 7 weeks and then treated with MPTP. (E) The number of TH-positive cells in the unilateral $\mathrm{SNpc}$ is presented as the mean $\pm \mathrm{SD}$. (J) The immunohistochemical staining intensity value for DAT in the unilateral striatum is presented as the mean $\pm \mathrm{SD}$; the value of saline control is set as 1.0 . ${ }^{*} p<0.05$ versus the mice fed the basal diet and treated with MPTP; ** $p<0.05$ versus the mice fed the basal diet and treated with saline. Scale bar: A-D, $100 \mu \mathrm{m} ; \mathrm{F}-\mathrm{I}, 500 \mu \mathrm{m}$.

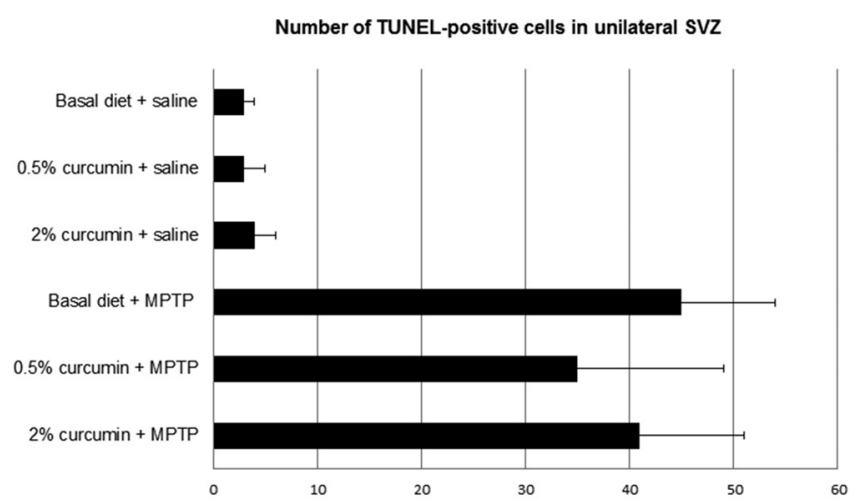

Fig. 2. Quantitative analysis of apoptotic cells by the TUNEL assay. There is no significant difference between the groups treated with MPTP and fed with or without curcumin. Data are shown as the mean $\pm \mathrm{SD}$.

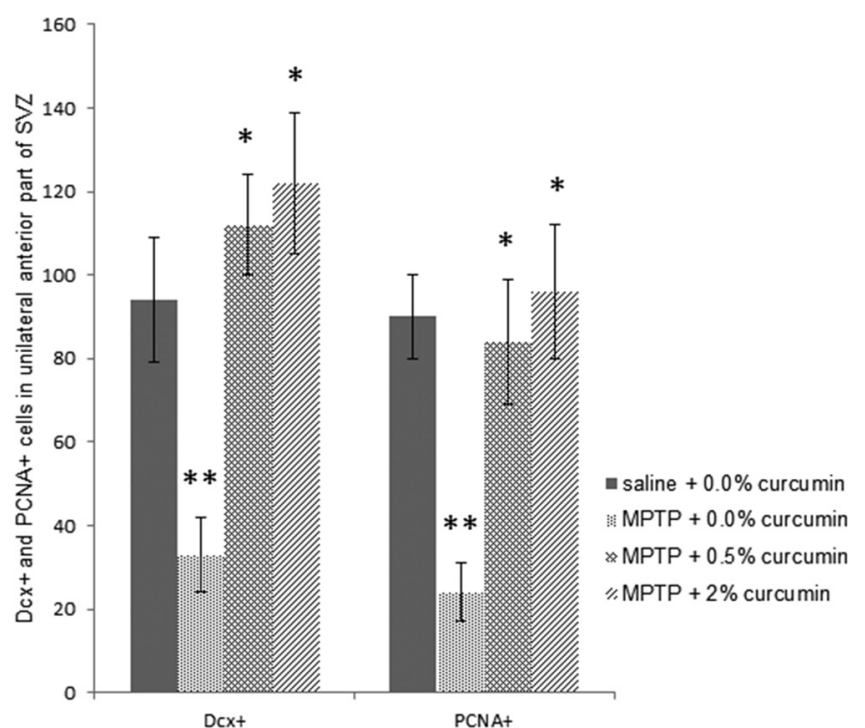

Fig. 4. Quantitative analysis of cells in the bilateral SVZa with immunohistochemical staining by using an anti-Dcx or anti-PCNA antibody. The number of Dcx + or PCNA+ cells is presented as the mean \pm SD. ${ }^{*} p<0.05$ versus the mice fed the basal diet and treated with MPTP; $* * p<0.05$ versus the mice fed the basal diet and treated with saline. 

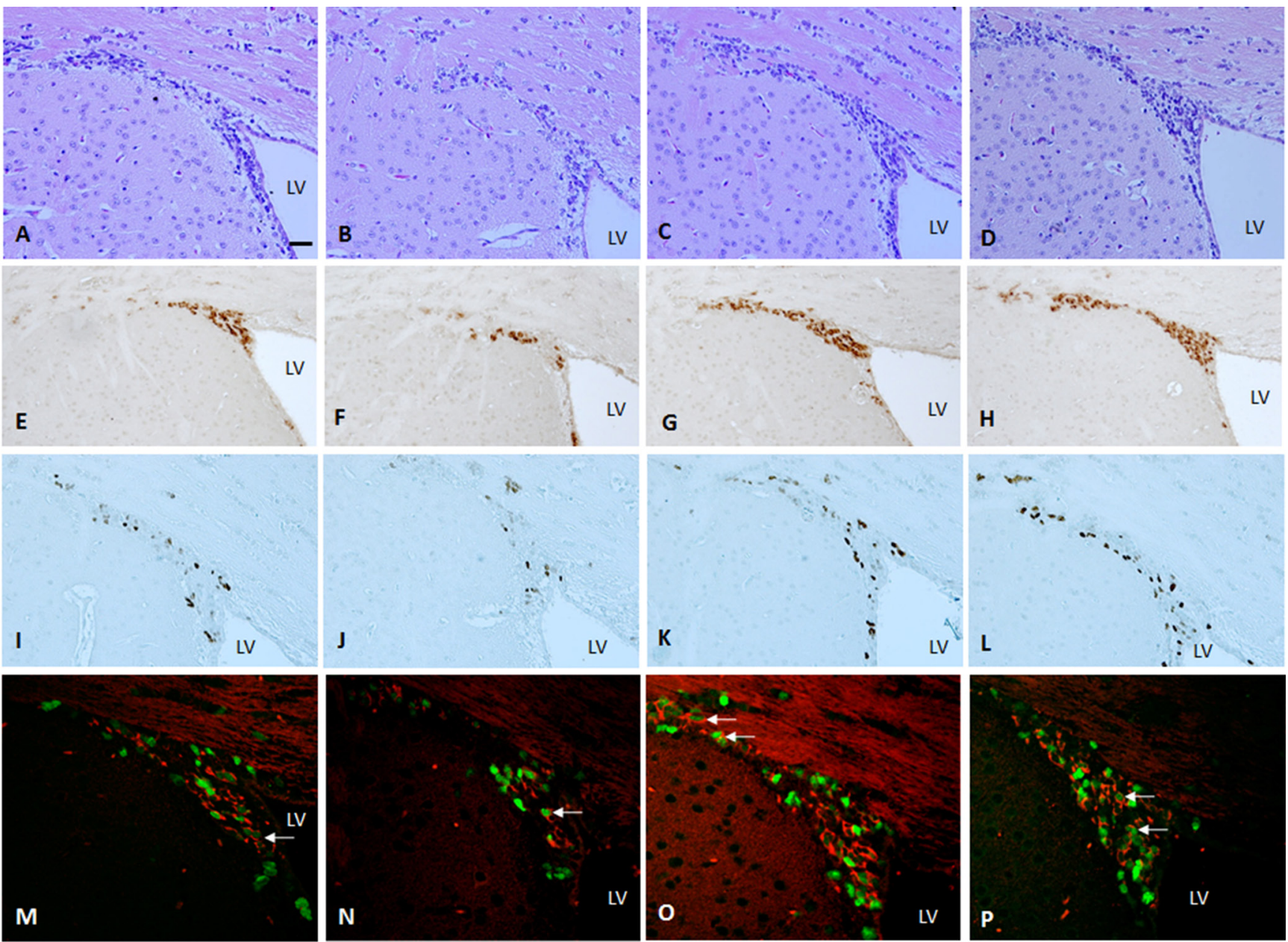

Fig. 3. Curcumin promotes the regeneration of neuroblasts in the SVZa post treatment with MPTP. Representative microphotographs of sections of the SVZa are stained with HE (A-D), Dcx (E-H), and PCNA (I-L) and double labled with Dcx (red) and PCNA (green) (M-P). (A, E, I and M) Control group (basal diet + saline). (B, F, J and N) Animals fed the basal diet and treated with MPTP showed a severe loss of neuroblasts in the SVZa. (C, G, K and O) Animals fed a diet supplemented with $0.5 \%(\mathrm{w} / \mathrm{w})$ curcumin for 7 weeks and then treated with MPTP. (D, H, L and P) Animals fed a diet supplemented with $2 \%(w / w)$ curcumin for 7 weeks and then treated with MPTP. Arrows in M-P show representative Dcx and PCNA double-labeled cells. LV, lateral ventricle. Scale bar: $20 \mu \mathrm{m}$.

PCNA and Dcx. Representative sections from mice fed the $0.5 \%$ (Fig. 3O) and $2 \%$ (Fig. 3P) curcumin diets showed that the majority of cells expressing Dcx were also positive for PCNA in the SVZa at 3 days post treatment. Curcumin itself did not change the number of Dcx- or PCNA-positive cells in saline-treated mice (data not shown).

\section{Dietary curcumin enhances the MPTP-induced acti- vation of microglia and astrocytes in the striatum}

As documented previously by other investigators, damage to the brain of adult rodents caused by MPTP resulted in glial activation in the nigrostriatal system ${ }^{7,22-24}$. In the MPTP-treated mice fed the basal diet, an increased number of GFAP-positive cells was observed in the striatum at 3 days post treatment (Fig. 5B and F, Fig. 6). Mice fed the diet supplemented with $0.5 \%$ or $2 \%$ curcumin showed further increases in GFAP-positive cells. As shown in Fig. 5C and $\mathrm{D}$ and $\mathrm{G}$ and $\mathrm{H}$ and Fig. 6, the activation of astrocytes was more prominent in the curcumin-treated groups than in the basal diet-fed group at 3 days after the MPTP treatment. The changes in both the number and morphology of astrocytes demonstrate that dietary curcumin supplementation results in a more extensive and enhanced activation of astrocytes in the striatum in MPTP-treated mice.

In order to examine the microglial activation, an immunohistochemical analysis was performed using an antibody raised against Iba 1 . The results showed that Iba $1 \mathrm{im}-$ munoreactivity was also induced in the striatum in mice fed the basal diet at 3 days post treatment with MPTP (Fig. 5J and N). The MPTP-induced microglial activation was more prominent in mice fed the curcumin supplement (Fig. $5 \mathrm{~K}$ and $\mathrm{L}$ and $\mathrm{O}$ and $\mathrm{P}$, Fig. 6) than in those fed only the basal diet.

Curcumin did not enhance the activation of microglia and astrocytes in the SNpc in MPTP-treated mice. Curcumin itself did not induce alterations to microglia and astro- 


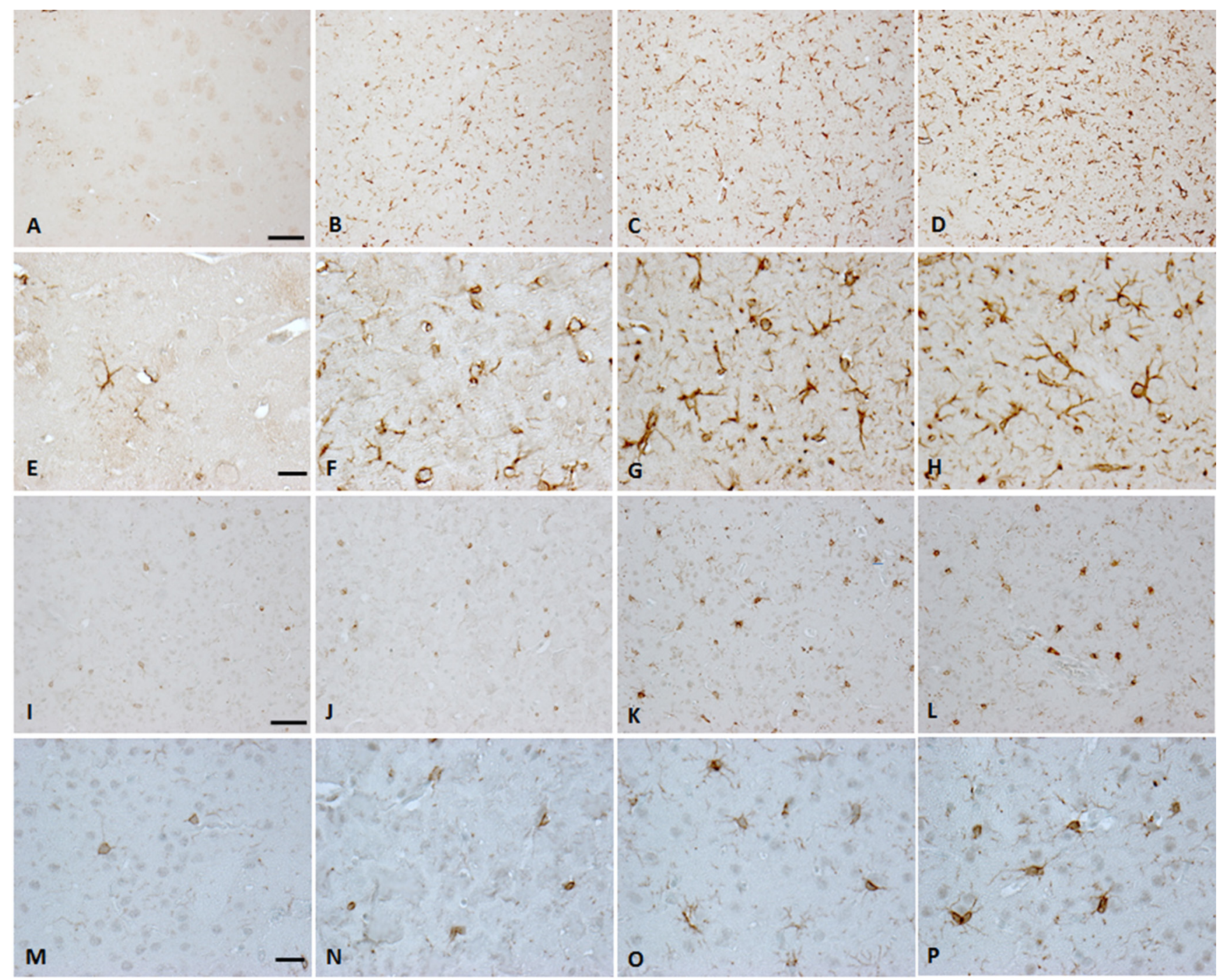

Fig. 5. Curcumin enhances the activation of astrocytes and microglia in the striatum post treatment with MPTP. Representative microphotographs of sections of the striatum are stained for GFAP (A-H) and Iba 1 (I-P). (A, E, I, and M) Control group (basal diet + saline). (B, F, $\mathrm{J}$ and N) Animals fed the basal diet and treated with MPTP showed increased expression of GFAP (B and F) and Iba 1 (I and N). (C, G, $\mathrm{K}$ and $\mathrm{O}$ ) Animals fed a diet supplemented with $0.5 \%(\mathrm{w} / \mathrm{w})$ curcumin for 7 weeks and then treated with MPTP. (D, H, L and P) Animals fed a diet supplemented with $2 \%(\mathrm{w} / \mathrm{w})$ curcumin for 7 weeks and then treated with MPTP. (E-H) Higher magnification of A-D. (M-P) Higher magnification of I-L. Scale bar: A-D and I-L, $50 \mu \mathrm{m}$; E-H and M-P, $20 \mu \mathrm{m}$.

cytes in the striatum or SNpc in saline-treated mice (data not shown).

\section{Dietary curcumin increases the expression of GDNF and TGF $B-1$ in the striatum and SVZ post treatment with MPTP}

Since the activation of microglia and astrocytes has been suggested to be neuroprotective, and these cells produce neurotrophic and/or neuroprotective factors after acute brain damage ${ }^{25,26}$, we evaluated the immunohistochemical expression of glial-derived factors, GDNF and TGF $\beta 1$, in the nigrostriatal system 3 days after MPTP treatment. Compared with saline- or MPTP-treated mice fed the basal diet (Fig. 7), the mice given curcumin showed an increase in GDNF and TGF $\beta 1$ staining in the striatum and SVZ (Fig. 7).
Increased GDNF and TGF $\beta 1$ expression was not detected in the SNpc. Curcumin itself did not change the immunohistochemical expression of GDNF or TGF $\beta 1$ in saline-treated mice (data not shown).

\section{Discussion}

Several mechanisms may be involved in the neurotoxicity of MPTP in the nigrostriatal system. Although no single mechanism is universally recognized, the initial sequence of events, the conversion of MPTP into $\mathrm{MPP}^{+}$, the real toxin, through the metabolization of monoamine oxidase B (MAO-B), appears to be well accepted. Curcumin has been reported to dose-dependently inhibit MAO-B activity in the mouse brain ${ }^{27}$. Rajeswari and Sabesan ${ }^{17}$ have 


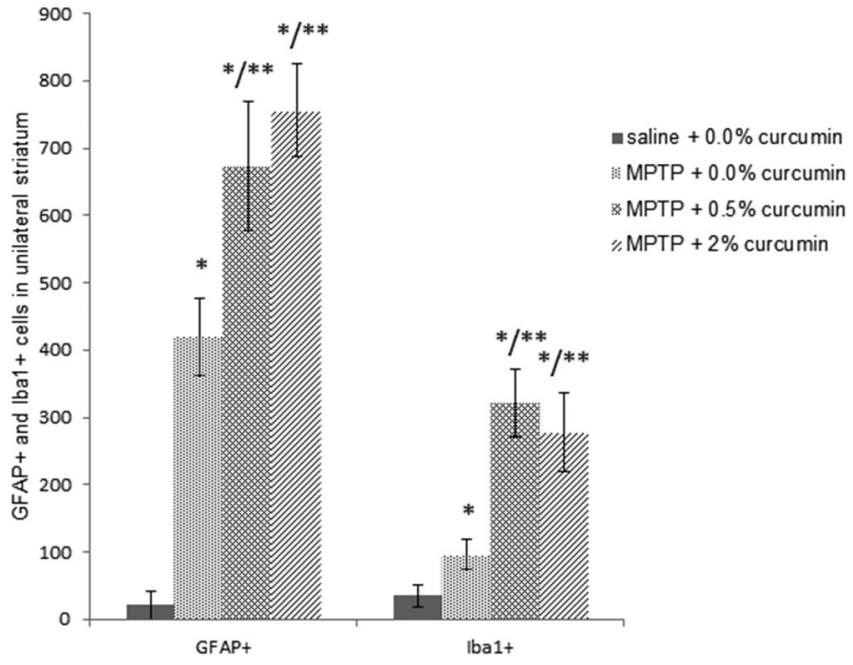

Fig. 6. Quantitative analysis of cells in the unilateral striatum with immunohistochemical staining by using an anti-GFAP or antiIba antibody. The number of GFAP+ or Iba1+ cells is presented as the mean $\pm \mathrm{SD} . * p<0.05$ versus the mice fed the basal diet and treat with saline; ${ }^{* *} p<0.05$ versus the mice fed the basal diet and treated with MPTP.

further demonstrated neuroprotective effects of curcumin, mediated by the inhibition of MAO-B activity, in mouse models of PD. We previously showed that pretreatment with a MAO-B inhibitor, such as R(-)-deprenyl (deprenyl) or N-(2-aminoethyl)-4-chlorobenzamide (Ro 16-6491), inhibited not only injury to the nigrostriatal dopaminergic system but also the apoptosis of neuroblasts induced by MPTP $^{9}$, suggesting that MAO-B also plays a crucial role in the apoptosis. Under our conditions, dietary curcumin did not provide any obvious protection against the MAO-B-mediated neurotoxicity of MPTP in neuroblasts in the SVZ, that is, long-term supplementation of the diet did not suppress the MPTP-induced apoptosis of neuroblasts, indicating no direct correlation between MAO-B activity and curcumin.

Once inside dopaminergic neurons, $\mathrm{MPP}^{+}$is concentrated by an active process within the mitochondria, where it impairs mitochondrial respiration by inhibiting complex I of the electron transport chain ${ }^{28}$. Complex I's inhibition by $\mathrm{MPP}^{+}$can directly result in increased oxidative stress ${ }^{29}$, which is suggested to be responsible for the neurotoxic effect of MPTP on the nigrostriatal dopaminergic system ${ }^{30}$. Numerous groups have provided evidence that curcumin exerts neuroprotective activity through antioxidative mechanisms. Rajeswari $^{16}$ and $\mathrm{Yu}$ et al. ${ }^{18}$ demonstrated that curcumin played an important role in preventing oxidative damage in the nigrostriatal dopaminergic system in an MPTP-induced animal model of PD, suggesting that the antioxidative mechanisms are also involved in the neuroprotective effects of curcumin administered a long term.

The present study also confirms results of previous investigations ${ }^{7,31}$ indicating that the activation of microglia and astrocytes occurs in the striatum in MPTP-treated mice.
Moreover, long-term dietary supplementation with curcumin enhanced the activation of microglia and astrocytes as revealed by GFAP and Iba 1 immnoreactivity, which was accompanied by increased expression of GDNF and TGF- $\beta 1$ in the striatum and SVZ. Although numerous findings now suggest that inflammation is involved in MPTP-mediated nigrostriatal neurodegeneration ${ }^{22,32,33}$, as well as other types of nigrostriatal neurodegeneration, there is no consensus regarding the significance of the role of inflammation in dopaminergic neuronal cell loss ${ }^{34}$. On the other hand, activated microglia or astrocytes also have neuroprotective effects mediated by the release of neurotrophins, uptake of glutamate and sequestering of neurotoxic substances ${ }^{26}$,

35. Neurotrophins such as GDNF and TGF $\beta 1$ are thought to play an important role in protecting neurons from injury in the central or peripheral nervous system. GDNF belongs to the TGF $\beta$ superfamily and is produced in microglia and astrocytes, and its mRNA has been detected in the microglia of the injured striatum ${ }^{25}$. TGF- $\beta 1$ is expressed in most CNS cell types and is rapidly up-modulated, mainly in astrocytes and microglia, after neural injury ${ }^{36}$. GDNF has been shown to exert pro-survival effects on dopaminergic neurons in an animal model of PD induced using MPTP ${ }^{37,38}$. Although an in vivo investigation was note performed, TGF- $\beta 1$ promoted the survival of dopaminergic neurons cultured from the embryonic rat mesencephalon floor after N-methyl-4-phenylpyridinium treatment ${ }^{39}$. Thus, enhanced activation of microglia and astrocytes by curcumin may be responsible for protecting the nigrostriatal dopaminergic system from MPTP neurotoxicity mediated by the excessive release of GDNF and TGF $\beta 1$. Even though inflammatory cytokines may also be produced in activated microglia and astrocytes, their levels could be suppressed by curcumin ${ }^{40,41}$.

The present results show that dietary curcumin supplementation promoted the regeneration of neuroblasts in the SVZa after MPTP-induced apoptosis, indicating a positive link between curcumin and neural regeneration, as described previously ${ }^{42}$. Previous evidence showing that GDNF or TGF $\beta 1$ is associated with neural proliferation ${ }^{43,44}$ may suggest that the enhanced activation of microglia and astrocytes caused by curcumin contributes not only to the dopaminergic system in the striatum and SNpc but also to neuroblast regeneration in the SVZa. Additional study will be required to clarify the other mechanisms involved in the curcumin-enhanced neurogenesis after MPTP-induced injury.

In conclusion, pretreatment for 7 weeks with a diet supplemented with $0.5 \%$ or $2 \%$ curcumin effectively protected the nigrostriatal dopaminergic system from the neurotoxicity of MPTP in C57BL/6 mice. The protective effect was clearly not dose dependent. The findings of the present study demonstrate that curcumin, when administered as a dietary supplement for a long term, protects against the neurotoxicity of MPTP in the nigrostriatal dopaminergic system and promotes the regeneration of neuroblasts in the SVZ in mice, and that this is likely due to the enhanced activation of microglia and astrocytes. 


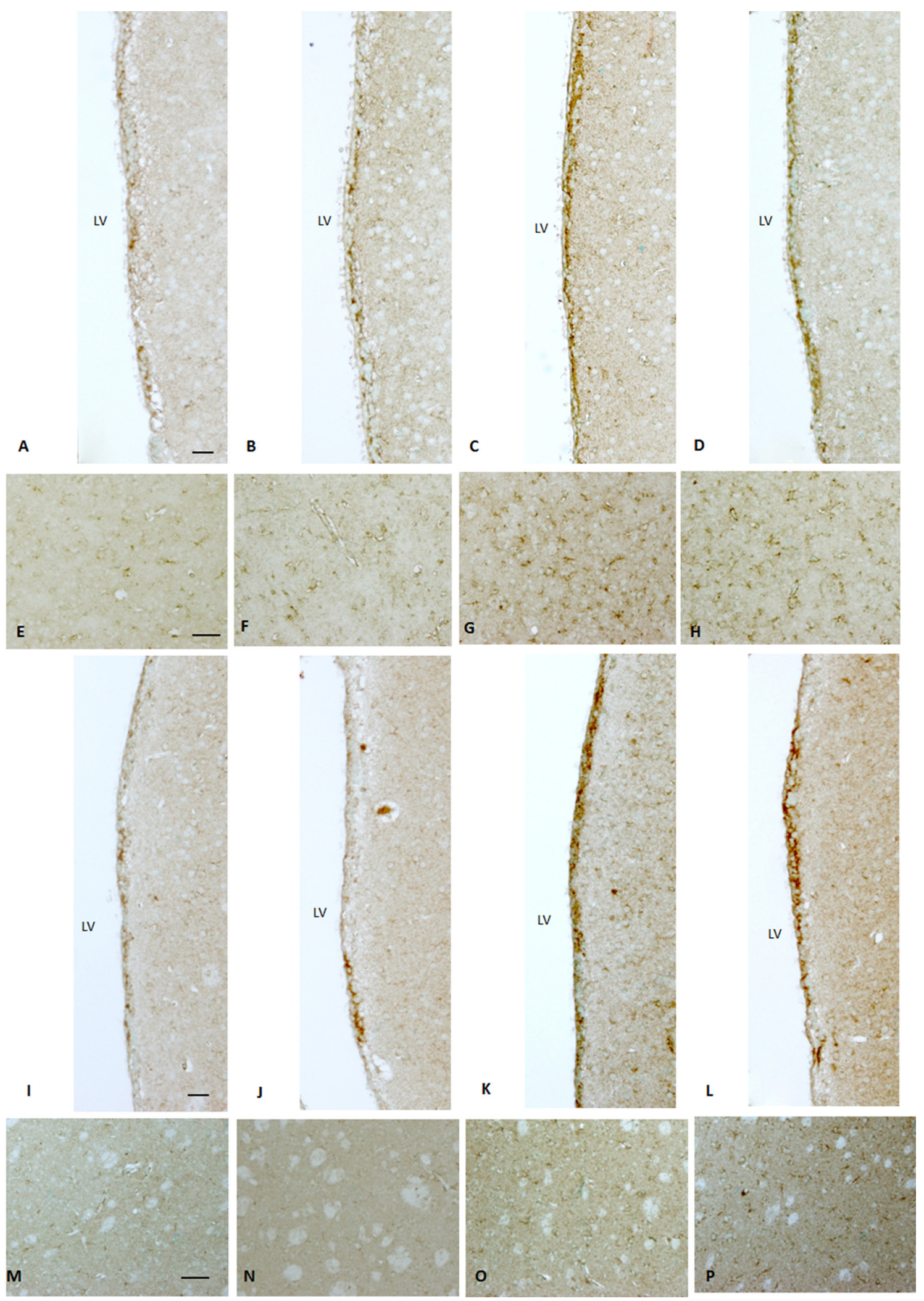

Fig. 7. Curcumin increases the expression of GDNF and TGF $\beta-1$ in the striatum and SVZ post treatment with MPTP. Representative microphotographs of sections of the SVZ (A-D, I-L) and striatum (E-H, M-P) stained for GDNF (A-H) or TGF $\beta-1$ (I-P). (A, E, I and M) Control group (basal diet + saline). (B, F, J and N) Animals fed the basal diet and treated with MPTP. (C, G, K and O) Animals fed a diet supplemented with $0.5 \%(\mathrm{w} / \mathrm{w})$ curcumin for 7 weeks and then treated with MPTP. (D, H, L and P) Animals fed a diet supplemented with $2 \%(\mathrm{w} / \mathrm{w})$ curcumin for 7 weeks and then treated with MPTP. LV, lateral ventricle. Scale bar: A-D and I-L, $20 \mu \mathrm{m} ; \mathrm{E}-\mathrm{H}$ and M-P, $100 \mu \mathrm{m}$. 
Disclosure of Potential Conflicts of Interest: The authors declare that they have no competing interests.

\section{References:}

1. Langston JW, Langston EB, and Irwin I. MPTP-induced parkinsonism in human and non-human primates - clinical and experimental aspects. Acta Neurol Scand Suppl. 100: 49-54. 1984. [Medline]

2. Chiueh CC, Markey SP, Burns RS, Johannessen JN, Jacobowitz DM, and Kopin IJ. Neurochemical and behavioral effects of 1-methyl-4-phenyl-1,2,3,6- tetrahydropyridine (MPTP) in rat, guinea pig, and monkey. Psychopharmacol Bull. 20: 548-553. 1984. [Medline]

3. Heikkila RE, Cabbat FS, Manzino L, and Duvoisin RC. Effects of 1-methyl-4-phenyl-1,2,5,6-tetrahydropyridine on neostriatal dopamine in mice. Neuropharmacology. 23: 711-713. 1984. [Medline] [CrossRef]

4. Drechsel DA, and Patel M. Role of reactive oxygen species in the neurotoxicity of environmental agents implicated in Parkinson's disease. Free Radic Biol Med. 44: 1873-1886. 2008. [Medline] [CrossRef]

5. Francis JW, Von Visger J, Markelonis GJ, and Oh TH. Neuroglial responses to the dopaminergic neurotoxicant 1-methyl-4-phenyl-1,2,3,6-tetrahydropyridine in mouse striatum. Neurotoxicol Teratol. 17: 7-12. 1995. [Medline] [CrossRef]

6. Feng ZH, Wang TG, Li DD, Fung P, Wilson BC, Liu B, Ali SF, Langenbach R, and Hong JS. Cyclooxygenase-2-deficient mice are resistant to 1-methyl-4-phenyl1, 2, 3, 6-tetrahydropyridine-induced damage of dopaminergic neurons in the substantia nigra. Neurosci Lett. 329: 354-358. 2002. [Medline] [CrossRef]

7. Kohutnicka M, Lewandowska E, Kurkowska-Jastrzebska I, Członkowski A, and Członkowska A. Microglial and astrocytic involvement in a murine model of Parkinson's disease induced by 1-methyl-4-phenyl-1,2,3,6-tetrahydropyridine (MPTP). Immunopharmacology. 39: 167-180. 1998. [Medline] [CrossRef]

8. He XJ, Nakayama H, Dong M, Yamauchi H, Ueno M, Uetsuka K, and Doi K. Evidence of apoptosis in the subventricular zone and rostral migratory stream in the MPTP mouse model of Parkinson disease. J Neuropathol Exp Neurol. 65: 873-882. 2006. [Medline] [CrossRef]

9. He XJ, Uetsuka K, and Nakayama H. Neural progenitor cells are protected against MPTP by MAO-B inhibitors. Neurotoxicology. 29: 1141-1146. 2008. [Medline] [CrossRef]

10. He XJ, Yamauchi H, Uetsuka K, and Nakayama H. Neurotoxicity of MPTP to migrating neuroblasts: studies in acute and subacute mouse models of Parkinson's disease. Neurotoxicology. 29: 413-420. 2008. [Medline] [CrossRef]

11. Phan TT, See P, Lee ST, and Chan SY. Protective effects of curcumin against oxidative damage on skin cells in vitro: its implication for wound healing. J Trauma. 51: 927-931. 2001. [Medline] [CrossRef]

12. Cole GM, Teter B, and Frautschy SA. Neuroprotective effects of curcumin. Adv Exp Med Biol. 595: 197-212. 2007. [Medline] [CrossRef]

13. Sawada $H$, Ibi $M$, Kihara $T$, Honda $K$, Nakamizo $T$, Kanki R, Nakanishi M, Sakka N, Akaike A, and Shimo- hama S. Estradiol protects dopaminergic neurons in a MPP+Parkinson's disease model. Neuropharmacology. 42: 1056-1064. 2002. [Medline] [CrossRef]

14. Chen J, Tang XQ, Zhi JL, Cui Y, Yu HM, Tang EH, Sun SN, Feng JQ, and Chen PX. Curcumin protects PC12 cells against 1-methyl-4-phenylpyridinium ion-induced apoptosis by bcl-2-mitochondria-ROS-iNOS pathway. Apoptosis. 11: 943-953. 2006. [Medline] [CrossRef]

15. Vajragupta O, Boonchoong P, Watanabe H, Tohda M, Kummasud N, and Sumanont Y. Manganese complexes of curcumin and its derivatives: evaluation for the radical scavenging ability and neuroprotective activity. Free Radic Biol Med. 35: 1632-1644. 2003. [Medline] [CrossRef]

16. Rajeswari A. Curcumin protects mouse brain from oxidative stress caused by 1-methyl-4-phenyl-1,2,3,6-tetrahydropyridine. Eur Rev Med Pharmacol Sci. 10: 157-161. 2006. [Medline]

17. Rajeswari A, and Sabesan M. Inhibition of monoamine oxidase-B by the polyphenolic compound, curcumin and its metabolite tetrahydrocurcumin, in a model of Parkinson's disease induced by MPTP neurodegeneration in mice. Inflammopharmacology. 16: 96-99. 2008. [Medline] [CrossRef]

18. Yu S, Zheng W, Xin N, Chi ZH, Wang NQ, Nie YX, Feng WY, and Wang ZY. Curcumin prevents dopaminergic neuronal death through inhibition of the c-Jun N-terminal kinase pathway. Rejuvenation Res. 13: 55-64. 2010. [Medline] [CrossRef]

19. Franklin KBJ, and Paxinos G. The mouse brain in stereotaxic coordinates. Academic Press, San Diego. 1997.

20. Deshpande SS, Lalitha VS, Ingle AD, Raste AS, Gadre SG, and Maru GB. Subchronic oral toxicity of turmeric and ethanolic turmeric extract in female mice and rats. Toxicol Lett. 95: 183-193. 1998. [Medline] [CrossRef]

21. Gupta B, Kulshrestha VK, Srivastava RK, and Prasad DN. Mechanisms of curcumin induced gastric ulcer in rats. Indian J Med Res. 71: 806-814. 1980. [Medline]

22. Wu DC, Jackson-Lewis V, Vila M, Tieu K, Teismann P, Vadseth C, Choi DK, Ischiropoulos H, and Przedborski S. Blockade of microglial activation is neuroprotective in the 1-methyl-4-phenyl-1,2,3,6-tetrahydropyridine mouse model of Parkinson disease. J Neurosci. 22: 1763-1771. 2002. [Medline]

23. Sugama S, Yang L, Cho BP, DeGiorgio LA, Lorenzl S, Albers DS, Beal MF, Volpe BT, and Joh TH. Age-related microglial activation in 1-methyl-4-phenyl-1,2,3,6-tetrahydropyridine (MPTP)-induced dopaminergic neurodegeneration in C57BL/6 mice. Brain Res. 964: 288-294. 2003. [Medline] [CrossRef]

24. Tripanichkul W, Sripanichkulchai K, and Finkelstein DI. Estrogen down-regulates glial activation in male mice following 1-methyl-4-phenyl-1,2,3,6-tetrahydropyridine intoxication. Brain Res. 1084: 28-37. 2006. [Medline] [CrossRef]

25. Nakajima K, and Kohsaka S. Microglia: neuroprotective and neurotrophic cells in the central nervous system. Curr Drug Targets Cardiovasc Haematol Disord. 4: 65-84. 2004. [Medline] [CrossRef]

26. Trendelenburg G, and Dirnagl U. Neuroprotective role of astrocytes in cerebral ischemia: focus on ischemic preconditioning. Glia. 50: 307-320. 2005. [Medline] [CrossRef]

27. Kulkarni SK, Bhutani MK, and Bishnoi M. Antidepressant 
activity of curcumin: involvement of serotonin and dopamine system. Psychopharmacology (Berl). 201: 435-442. 2008. [Medline] [CrossRef]

28. Vila M, and Przedborski S. Targeting programmed cell death in neurodegenerative diseases. Nat Rev Neurosci. 4: 365-375. 2003. [Medline] [CrossRef]

29. Andersen JK. Oxidative stress in neurodegeneration: cause or consequence? Nat Med. 10(Suppl): S18-S25. 2004. [Medline] [CrossRef]

30. Liberatore GT, Jackson-Lewis V, Vukosavic S, Mandir AS, Vila M, McAuliffe WG, Dawson VL, Dawson TM, and Przedborski S. Inducible nitric oxide synthase stimulates dopaminergic neurodegeneration in the MPTP model of Parkinson disease. Nat Med. 5: 1403-1409. 1999. [Medline] [CrossRef]

31. Kurkowska-Jastrzebska I, Wrońska A, Kohutnicka M, Członkowski A, and Członkowska A. The inflammatory reaction following 1-methyl-4-phenyl-1,2,3, 6-tetrahydropyridine intoxication in mouse. Exp Neurol. 156: 50-61. 1999. [Medline] [CrossRef]

32. Sy HN, Wu SL, Wang WF, Chen CH, Huang YT, Liou YM, Chiou CS, Pawlak CR, and Ho YJ. MPTP-induced dopaminergic degeneration and deficits in object recognition in rats are accompanied by neuroinflammation in the hippocampus. Pharmacol Biochem Behav. 95: 158-165. 2010. [Medline] [CrossRef]

33. Vijitruth R, Liu M, Choi DY, Nguyen XV, Hunter RL, and Bing G. Cyclooxygenase-2 mediates microglial activation and secondary dopaminergic cell death in the mouse MPTP model of Parkinson's disease. J Neuroinflammation. 3: 6 . 2006. [Medline] [CrossRef]

34. Yokoyama H, Kuroiwa H, Yano R, and Araki T. Targeting reactive oxygen species, reactive nitrogen species and inflammation in MPTP neurotoxicity and Parkinson's disease. Neurol Sci. 29: 293-301. 2008. [Medline] [CrossRef]

35. Takeuchi H, Jin S, Wang J, Zhang G, Kawanokuchi J, Kuno R, Sonobe Y, Mizuno T, and Suzumura A. Tumor necrosis factor-alpha induces neurotoxicity via glutamate release from hemichannels of activated microglia in an autocrine manner. J Biol Chem. 281: 21362-21368. 2006. [Medline] [CrossRef]

36. Wyss-Coray T, Borrow P, Brooker MJ, and Mucke L. Astroglial overproduction of TGF-beta 1 enhances inflammatory central nervous system disease in transgenic mice. J Neuroimmunol. 77: 45-50. 1997. [Medline] [CrossRef]

37. Tomac A, Lindqvist E, Lin LF, Ogren SO, Young D, Hoffer $\mathrm{BJ}$, and Olson L. Protection and repair of the nigrostriatal dopaminergic system by GDNF in vivo. Nature. 373: 335 339. 1995. [Medline] [CrossRef]

38. Kordower JH, Emborg ME, Bloch J, Ma SY, Chu Y, Leventhal L, McBride J, Chen EY, Palfi S, Roitberg BZ, Brown WD, Holden JE, Pyzalski R, Taylor MD, Carvey P, Ling Z, Trono D, Hantraye P, Déglon N, and Aebischer P. Neurodegeneration prevented by lentiviral vector delivery of GDNF in primate models of Parkinson's disease. Science. 290: 767-773. 2000. [Medline] [CrossRef]

39. Krieglstein K, Suter-Crazzolara C, Fischer WH, and Unsicker K. TGF-beta superfamily members promote survival of midbrain dopaminergic neurons and protect them against MPP+ toxicity. EMBO J. 14: 736-742. 1995. [Medline]

40. Jin CY, Lee JD, Park C, Choi YH, and Kim GY. Curcumin attenuates the release of pro-inflammatory cytokines in lipopolysaccharide-stimulated BV2 microglia. Acta Pharmacol Sin. 28: 1645-1651. 2007. [Medline] [CrossRef]

41. Tomita M, Holman BJ, Santoro CP, and Santoro TJ. Astrocyte production of the chemokine macrophage inflammatory protein-2 is inhibited by the spice principle curcumin at the level of gene transcription. J Neuroinflammation. 2: 8. 2005. [Medline] [CrossRef]

42. Xu Y, Ku B, Cui L, Li X, Barish PA, Foster TC, and Ogle WO. Curcumin reverses impaired hippocampal neurogenesis and increases serotonin receptor 1A mRNA and brain-derived neurotrophic factor expression in chronically stressed rats. Brain Res. 1162: 9-18. 2007. [Medline] [CrossRef]

43. Kobayashi T, Ahlenius H, Thored P, Kobayashi R, Kokaia $\mathrm{Z}$, and Lindvall $\mathrm{O}$. Intracerebral infusion of glial cell linederived neurotrophic factor promotes striatal neurogenesis after stroke in adult rats. Stroke. 37: 2361-2367. 2006. [Medline] [CrossRef]

44. Battista D, Ferrari CC, Gage FH, and Pitossi FJ. Neurogenic niche modulation by activated microglia: transforming growth factor beta increases neurogenesis in the adult dentate gyrus. Eur J Neurosci. 23: 83-93. 2006. [Medline] [CrossRef] 